\title{
Poor Quality Image
}

National Cancer Institute

\section{Source}

National Cancer Institute. Poor Quality Image. NCI Thesaurus. Code C62869.

Inadequate quality of an image or any visual representation displayed by the device, or output from the device. 